\title{
COMPARISON OF THE FEMORAL HEAD HEIGHT/NECK LENGTH RATIO BETWEEN THE UNAFFECTED HIP OF PATIENTS WITH A UNILATERAL SLIPPED FEMORAL HEAD AND THE HIPS OF INDIVIDUALS WITHOUT A SLIPPED FEMORAL HEAD
}

Paulo Santoro Belangero', Thiago Amorim Bastos', Glauber Kazuo Linhares', Patrícia Corey Yamane², Paulo Ivan Miyagi ${ }^{3}$, Sérgio Satoshi Kuwajima ${ }^{4}$, Akira Ishida ${ }^{5}$

\section{ABSTRACT}

Objective - To compare the head/neck ratio on the contralateral side of patients with a unilateral slipped capital femoral epiphysis (SCFE) with control individuals. Methods - Seventeen patients who were followed up at the Department of Orthopedics and Traumatology, Federal University of São Paulo, Brazil, between 1985 and 2007, were assessed. The control group consisted of 34 individuals from the same place who were matched for gender and age, with a history of trauma that necessitated pelvic radiography. The femoral head height and femoral neck measurements were made using simple pelvic radiography in accordance with the criteria of Bleck (1983), on both sides in the control group and on the contralateral hip in the patients. Nonparametric statistics were used, with a p-value $\leq 0.05$. Results - There was no difference in the distribution of age, gender, body mass index and bone age between the groups. The head/neck ratio on the right and left side in the controls did not differ $(\mathrm{p}=0.64)$. However, the head/neck ratio from the contralateral hip of the patients with SCFE was significantly lower than that of the control group $(p=0.00)$. Conclusion - The significantly lower head/neck ratio in the patients with epiphysiolysis could be indicative of a risk of SCFE.

Keywords - Epiphysis, Slipped; Femoral Head; Risk Factors.

\section{INTRODUCTION}

Proximal epiphysiolysis of the femur (PEF) is the commonest hip disease during preadolescence and adolescence $^{(1,2)}$. It is more frequent among males and in the presence of obesity or overweight ${ }^{(2)}$. Although the etiology is unknown, it is related to biological and mechanical factors ${ }^{(1-6)}$. Among the biological factors, hormones, age, pubertal development and skeletal maturation have been considered. Thus, increased levels of FSH, LH or testosterone, or use of GH, have been cited as factors favoring $\mathrm{PEF}^{(3)}$.

The initial presentation of epiphysiolysis is generally unilateral, but involvement of the contralateral side may occur in up to $80 \%$ of the cases, depending on age, gender, hormonal disorders and bone maturation

\footnotetext{
1 - Resident in the Department of Orthopedics and Traumatology, Federal University of São Paulo.

2 - Postgraduate Student in the Department of Orthopedics and Traumatology, Federal University of São Paulo.

3 - Attending Physician in the Department of Orthopedics and Traumatology, Federal University of São Paulo.

4 - PhD from the Department of Orthopedics and Traumatology, Federal University of São Paulo.

5 - Titular Professor of the Department of Orthopedics and Traumatology, Federal University of São Paulo.
}

Work performed in the Discipline of Pediatric Orthopedics, Department of Orthopedics and Traumatology, Federal University of São Paulo. Correspondence: Departamento de Ortopedia e Traumatologia da Universidade Federal de São Paulo.

Rua Borges Lagoa 783, $5^{\circ}$ andar - Vila Clementino - 04038-032 - São Paulo, SP. E-mail: psbelangero@yahoo.com.br

Work received for publication: January 17, 2010, accepted for publication: July 19, 2010. 
phase, among other factors ${ }^{(7)}$. This has caused much polemic in the literature, with regard to whether or not prophylactic contralateral epiphysiodesis should be indicated. Both the dynamic parameters (bone age, chronological age and hormone profile) and the anatomical parameters (retroversion of the neck and growth plate-neck angle) have been studied with the objective of finding predictive determinants that might provide the basis for a surgical approach to the hip, in the absence of symptoms. Puylaert et $\mathrm{al}^{(4)}$ demonstrated that more than $60 \%$ of PEF cases were in Tanner's pubertal stage 1 , with the triradiate cartilage open and therefore in an opportune condition for contralateral slippage. Staging of puberty is considered to be an important parameter. Bidwell and Stott, among others, considered that PEF before the age of 12 years was a risk factor for contralateral slippage, independent of the patient's gender ${ }^{(8)}$. However, there are authors who have not correlated the risk of PEF with age ${ }^{(9)}$. Data on skeletal maturation as a protection factor (when advanced) or a risk factor (when delayed) have been highlighted. In 1996, Stasikelis et $\mathrm{al}^{(10)}$ evaluated skeletal maturity using a modified Oxford method among a group of patients with PEF, and concluded that there was a linear correlation between the risk of new slippage and bone maturation. When the Oxford score was less than 16 , there was an $85 \%$ risk of a second episode of PEF; however, if the score was 21 , the risk was $11 \%$, and if it was more than 22 , PEF would not occur ${ }^{(10)}$. Recently, Loder et $\mathrm{al}^{(11)}$ assessed the difference between chronological age and bone age among patients with PEF, using the modified Oxford method, and concluded that the interval of bone age within which epiphysiolysis occurred was only 15 months. Among the anatomical indices so far evaluated, we did not find any studies on the relationship between femoral head height and neck length. Thus, the aim of the study was to compare the head/neck ratio in the contralateral hip of patients with epiphysiolysis, with a control group.

\section{OBJECTIVES OF THE STUDY}

To compare the head/neck ratio of the contralateral side of patients with unilateral epiphysiolysis, with a control group matched according to age and gender.

Rev Bras Ortop. 2011;46(1):57-63

\section{SAMPLE AND METHODS}

\section{Type of study}

This was a retrospective cross-sectional non-randomized study with a control group. This study was approved by the Research Ethics Committee of Unifesp, under the number 0361/07.

The study group (group 1) was formed by all the patients with a diagnosis of unilateral PEF followed up at Hospital São Paulo between 1985 and 2007. Only the patients with an asymptomatic contralateral hip who did not present radiographic signs of PEF on this side were included. The data on each patient were obtained from the medical files and from radiographs.

The control group (group 2) was formed by individuals attended at Hospital São Paulo during 2007, with a history of trauma or a complaint of pain in the hip or pelvis that justified producing a radiograph of the pelvis, but without finding any abnormalities at the end of the assessment. These individuals were selected in accordance with the age and gender of the study group patients, at a ratio of two controls for every case in group 1.

Simple radiographs of the pelvis in anteroposterior and Lauenstein views were used, along with the data from the initial consultation that appeared in the medical files: gender, age, color, side affected by the epiphysiolysis, weight and height.

\section{Radiographic evaluation}

On a radiograph of the pelvis in anteroposterior view with the limbs in the neutral position, the length of the femoral neck, the height and the diameter of the proximal epiphysis of the femur were measured on the hip contralateral to the epiphysiolysis, and in both hips of the controls, based on the method described by Bleck ${ }^{(12)}$.

\section{Method for measurements}

By means of Mose concentric circles, the center of the femoral head and the center of the neck were determined. A straight line ("AB") was drawn through these two points and was extended from the lateral cortical bone of the femur to the proximal joint extremity of the head. Next, a straight line ("CD") was drawn, joining the two ends of the epiphyseal plate of the femoral neck. This line represented the width of the head. It interested with the straight line AB at 
point $\mathrm{C}$, thus cutting it into two parts: segment "a", going from the lateral cortex of the diaphysis to point $\mathrm{C}$, which corresponded to the length of the femoral neck; and segment " $b$ ", going from point $\mathrm{C}$ to the proximal joint end of the head, which was taken to be the head height (Figure 1).

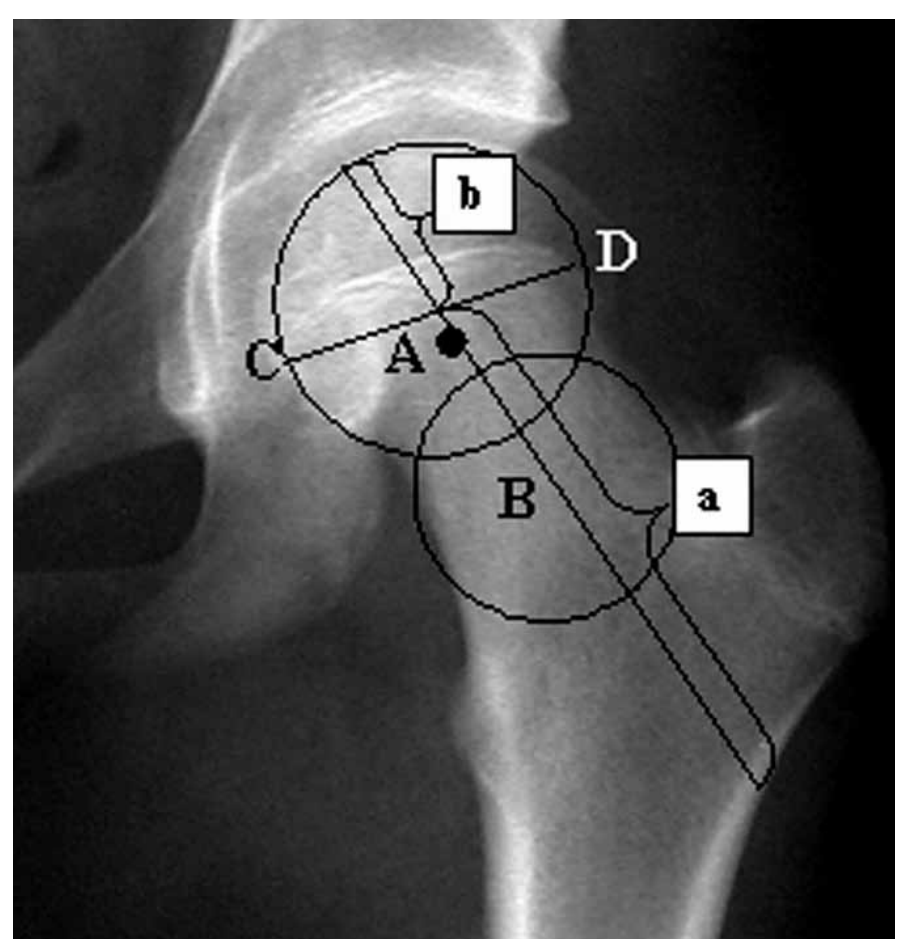

Figure 1 - Diagram showing measurement of segments $a$ and $b$.

\section{DETERMINATION OF BMI AND BONE AGE ACCORDING TO OXFORD}

From the weight and height measurements, the body mass index (BMI) was calculated. The BMI values were classified in accordance with the standardization of Must et $\mathrm{al}^{(13)}$. According to these authors, individuals with BMI values lower than the $5^{\text {th }}$ percentile are considered to be malnourished; between the $5^{\text {th }}$ and $85^{\text {th }}$ percentiles, they are normal; between the $85^{\text {th }}$ and $95^{\text {th }}$ percentiles, they are overweight; and greater than or equal to the $95^{\text {th }}$ percentile, they are obese.

Bone age was assessed using the initial radiographs on the pelvis, in accordance with the modified Oxford method ${ }^{(14)}$. This method uses simple radiographs of the pelvis, in anteroposterior view, including the iliac crest and the proximal thirds of the femurs. Nine radiographic parameters are scored, which vary according to the individual's stage of ma- turation $^{(14)}$. In analyzing the Oxford scores, the normal values for each age group and gender were taken to be the mean \pm one standard deviation, similarly to what was done in the study by Ishida et $\mathrm{al}^{(15)}$.

\section{COMPARISON OF MEASUREMENTS}

The absolute values obtained after measuring the lengths of the segments $a$ and $b$, and the ratio $\mathrm{b} / \mathrm{a}$ (head height/neck length measurement), were analyzed comparatively between groups 1 and 2 .

\section{STATISTICAL ANALYSIS}

To compare between the groups, the Mann-Whitney $U$ test was used. For comparisons within the same group, the nonparametric Wilcoxon test was used. For all the tests, the $\mathrm{p}$ value was 0.05 .

\section{RESULTS}

Seventeen patients and 34 controls were studied. Their general characteristics are presented in Tables 1 and 2.

Table 1 - General characteristics of the group of patients with proximal epiphysiolysis of the femur.

\begin{tabular}{c|c|c|c|c|c}
\hline $\begin{array}{c}\text { Patients' } \\
\text { serial } \\
\text { numbers }\end{array}$ & Gender & $\begin{array}{c}\text { Age } \\
\text { (years) }\end{array}$ & Side & $\begin{array}{c}\text { Degree of } \\
\text { epiphysiolysis }\end{array}$ & Oxford score \\
\hline 1 & $\mathrm{M}$ & 11.00 & $\mathrm{R}$ & $\mathrm{II}$ & 30.00 \\
\hline 2 & $\mathrm{M}$ & 12.00 & $\mathrm{R}$ & $\mathrm{III}$ & 33.00 \\
\hline 3 & $\mathrm{M}$ & 14.00 & $\mathrm{~L}$ & $\mathrm{II}$ & 32.00 \\
\hline 4 & $\mathrm{~F}$ & 12.00 & $\mathrm{~L}$ & $\mathrm{III}$ & 32.00 \\
\hline 5 & $\mathrm{M}$ & 15.00 & $\mathrm{~L}$ & $\mathrm{I}$ & 32.00 \\
\hline 6 & $\mathrm{M}$ & 11.00 & $\mathrm{~L}$ & $\mathrm{I}$ & 33.00 \\
\hline 7 & $\mathrm{~F}$ & 9.00 & $\mathrm{~L}$ & $\mathrm{I}$ & 31.00 \\
\hline 8 & $\mathrm{~F}$ & 13.00 & $\mathrm{~L}$ & $\mathrm{I}$ & 31.00 \\
\hline 9 & $\mathrm{~F}$ & 12.00 & $\mathrm{~L}$ & $\mathrm{I}$ & 30.00 \\
\hline 10 & $\mathrm{~F}$ & 10.00 & $\mathrm{~L}$ & $\mathrm{I}$ & 33.00 \\
\hline 11 & $\mathrm{M}$ & 15.00 & $\mathrm{~L}$ & $\mathrm{I}$ & 32.00 \\
\hline 12 & $\mathrm{M}$ & 12.00 & $\mathrm{~L}$ & $\mathrm{I}$ & 31.00 \\
\hline 13 & $\mathrm{~F}$ & 11.00 & $\mathrm{~L}$ & $\mathrm{III}$ & 32.00 \\
\hline 14 & $\mathrm{~F}$ & 11.00 & $\mathrm{R}$ & $\mathrm{III}$ & 31.00 \\
\hline 15 & $\mathrm{M}$ & 15.00 & $\mathrm{~L}$ & $\mathrm{II}$ & 33.00 \\
\hline 16 & $\mathrm{~F}$ & 10.00 & $\mathrm{R}$ & $\mathrm{I}$ & 32.00 \\
\hline 17 & $\mathrm{~F}$ & 10.00 & $\mathrm{~L}$ & $\mathrm{I}$ & 29.00 \\
\hline $\mathrm{MEAN} \pm$ & & $11.9 \pm$ & & & $31.58 \pm 1.17$ \\
\hline SD & & 0.45 & & & \\
\hline
\end{tabular}


Table 2 - General characteristics of the control group.

\begin{tabular}{|c|c|c|c|}
\hline $\begin{array}{l}\text { Controls' serial } \\
\text { numbers }\end{array}$ & Gender & Age (years) & Oxford score \\
\hline 1 & $\mathrm{~F}$ & 14.00 & 42.00 \\
\hline 2 & $M$ & 11.00 & 31.00 \\
\hline 3 & $\mathrm{~F}$ & 9.00 & 26.00 \\
\hline 4 & $\mathrm{M}$ & 10.00 & 23.00 \\
\hline 5 & M & 12.00 & 25.00 \\
\hline 6 & $\mathrm{M}$ & 12.00 & 25.00 \\
\hline 7 & M & 11.00 & 23.00 \\
\hline 8 & $\mathrm{~F}$ & 11.00 & 29.00 \\
\hline 9 & $\mathrm{M}$ & 14.00 & 31.00 \\
\hline 10 & $\mathrm{~F}$ & 10.00 & 26.00 \\
\hline 11 & $\mathrm{~F}$ & 10.00 & 26.00 \\
\hline 12 & $\mathrm{~F}$ & 11.00 & 25.00 \\
\hline 13 & $\mathrm{~F}$ & 12.00 & 36.00 \\
\hline 14 & $\mathrm{~F}$ & 12.00 & 32.00 \\
\hline 15 & $\mathrm{~F}$ & 9.00 & 33.00 \\
\hline 16 & M & 13.00 & 29.00 \\
\hline 17 & M & 14.00 & 30.00 \\
\hline 18 & $\mathrm{~F}$ & 12.00 & 32.00 \\
\hline 19 & M & 12.00 & 30.00 \\
\hline 20 & M & 13.00 & 28.00 \\
\hline 21 & $\mathrm{M}$ & 10.00 & 27.00 \\
\hline 22 & M & 12.00 & 30.00 \\
\hline 23 & $\mathrm{~F}$ & 12.00 & 30.00 \\
\hline 24 & $\mathrm{~F}$ & 11.00 & 31.00 \\
\hline 25 & $\mathrm{M}$ & 14.00 & 31.00 \\
\hline 26 & $\mathrm{~F}$ & 15.00 & 32.00 \\
\hline 27 & $\mathrm{~F}$ & 13.00 & 33.00 \\
\hline 28 & M & 13.00 & 34.00 \\
\hline 29 & $\mathrm{~F}$ & 11.00 & 32.00 \\
\hline 30 & M & 11.00 & 29.00 \\
\hline 31 & $\mathrm{M}$ & 14.00 & 35.00 \\
\hline 32 & $\mathrm{~F}$ & 9.00 & 31.00 \\
\hline 33 & $\mathrm{M}$ & 10.00 & 27.00 \\
\hline 34 & M & 13.00 & 38.00 \\
\hline Mean \pm SD & & $11.7 \pm 0.28$ & $30.05 \pm 4.15$ \\
\hline
\end{tabular}

The ages did not differ significantly between groups 1 and 2, with means of $11.9 \pm 0.45$ years and $11.7 \pm 0.28$ years, respectively $(p=0.63)$. The gender distribution also did not differ significantly, with eight male patients and 19 male controls $(\mathrm{p}=0.423)$.

The mean bone age in group 1 was $13.41 \pm 0.32$, and in group 2, $12.92 \pm 0.29$, without any significant difference between the groups $(\mathrm{p}=0.43)$. It was obRev Bras Ortop. 2011;46(1):57-63 served that, among the patients with epiphysiolysis, $7 / 17$ presented a normal bone age and 10/17 presented advanced bone age (greater than the mean + one standard deviation). In the control group, 17/34 presented normal bone age and the other half presented advanced bone age, without any significant difference $(p=0.38)$. However, in both groups, the bone age was significantly greater than the chronological age $(p=0.000)$.

The evaluation on the BMI showed that the mean value in group 1 was $21.59 \pm 3.9$ and in group 2, it was $21.05 \pm 5.8$, without any significant difference between the groups $(p=0.765)$, or in relation to gender $(p=0.46)$. Nonetheless, greater frequency of overweight and obese cases was observed in group 1 (50\% vs. $25.3 \%)$.

\section{FEMORAL HEAD HEIGHT/NECK RATIO}

The absolute values of the neck and head height measurements are presented in Tables 3 and 4 .

The head height measurements did not present any

Table 3 - Absolute values of the head height and neck measurements on the femur contralateral to the epiphysiolysis, and the head/neck ratio, in the patient group.

\begin{tabular}{|c|c|c|c|}
\hline $\begin{array}{c}\text { Patients' } \\
\text { serial } \\
\text { numbers }\end{array}$ & $\begin{array}{c}\text { Femoral head } \\
\text { height }(\mathrm{mm})\end{array}$ & $\begin{array}{c}\text { Femoral } \\
\text { neck }(\mathrm{mm})\end{array}$ & $\begin{array}{c}\text { Head/neck } \\
\text { ratio }\end{array}$ \\
\hline 1 & 2.35 & 8.00 & 0.294 \\
\hline 2 & 2.40 & 8.40 & 0.286 \\
\hline 3 & 2.60 & 9.40 & 0.277 \\
\hline 4 & 1.90 & 8.40 & 0.226 \\
\hline 5 & 2.30 & 9.30 & 0.247 \\
\hline 6 & 2.45 & 8.45 & 0.290 \\
\hline 7 & 2.10 & 7.60 & 0.276 \\
\hline 8 & 2.17 & 8.55 & 0.255 \\
\hline 9 & 2.00 & 8.70 & 0.230 \\
\hline 10 & 2.00 & 7.50 & 0.267 \\
\hline 11 & 2.00 & 9.50 & 0.211 \\
\hline 12 & 2.25 & 8.70 & 0.259 \\
\hline 13 & 1.70 & 8.40 & 0.202 \\
\hline 14 & 2.35 & 8.35 & 0.281 \\
\hline 15 & 2.20 & 9.40 & 0.234 \\
\hline 16 & 1.80 & 9.20 & 0.196 \\
\hline 17 & 2.35 & 8.00 & 0.294 \\
\hline Mean \pm SD & $2.17 \pm 0.25$ & $8.55 \pm 0.66$ & $0.255 \pm 0.03$ \\
\hline
\end{tabular}


Table 4 - Absolute values for the femoral head height and neck measurements, on the right and on the left in the control group, and the head/neck ratio.

\begin{tabular}{|c|c|c|c|c|c|c|c|}
\hline $\begin{array}{l}\text { Controls' serial } \\
\text { numbers }\end{array}$ & $\begin{array}{l}\text { Right head } \\
\text { height }\end{array}$ & Right neck & $\begin{array}{l}\text { Right head/neck } \\
\text { ratio }\end{array}$ & $\begin{array}{l}\text { Left head } \\
\text { height }\end{array}$ & Left neck & $\begin{array}{c}\text { Left head/neck } \\
\text { ratio }\end{array}$ & $\begin{array}{c}\text { Mean of the } \\
\text { ratios }\end{array}$ \\
\hline 1 & 2.30 & 8.20 & 0.28 & 2.30 & 8.10 & 0.28 & 0.28 \\
\hline 2 & 2.00 & 9.10 & 0.22 & 2.20 & 8.70 & 0.25 & 0.24 \\
\hline 3 & 2.20 & 7.00 & 0.31 & 2.10 & 7.10 & 0.30 & 0.31 \\
\hline 4 & 1.80 & 6.10 & 0.30 & 1.80 & 6.10 & 0.30 & 0.30 \\
\hline 5 & 2.30 & 8.30 & 0.28 & 2.40 & 8.40 & 0.29 & 0.28 \\
\hline 6 & 2.20 & 7.20 & 0.31 & 2.20 & 7.20 & 0.31 & 0.31 \\
\hline 7 & 2.40 & 7.70 & 0.31 & 2.40 & 7.80 & 0.31 & 0.31 \\
\hline 8 & 2.10 & 7.30 & 0.29 & 2.10 & 7.10 & 0.30 & 0.29 \\
\hline 9 & 2.00 & 8.30 & 0.24 & 2.00 & 8.30 & 0.24 & 0.24 \\
\hline 10 & 2.30 & 7.80 & 0.29 & 2.30 & 7.80 & 0.29 & 0.29 \\
\hline 11 & 2.30 & 8.30 & 0.28 & 2.30 & 8.30 & 0.28 & 0.28 \\
\hline 12 & 1.85 & 7.50 & 0.25 & 1.80 & 7.40 & 0.24 & 0.24 \\
\hline 13 & 2.20 & 8.30 & 0.27 & 2.30 & 8.00 & 0.29 & 0.28 \\
\hline 14 & 2.50 & 8.10 & 0.31 & 2.50 & 8.10 & 0.31 & 0.31 \\
\hline 15 & 2.30 & 7.90 & 0.29 & 2.30 & 7.70 & 0.30 & 0.29 \\
\hline 16 & 2.40 & 8.10 & 0.30 & 2.30 & 8.30 & 0.28 & 0.29 \\
\hline 17 & 2.40 & 8.30 & 0.29 & 2.40 & 8.40 & 0.29 & 0.29 \\
\hline 18 & 2.50 & 7.40 & 0.34 & 2.50 & 7.80 & 0.32 & 0.33 \\
\hline 19 & 2.30 & 7.70 & 0.30 & 2.30 & 8.90 & 0.26 & 0.28 \\
\hline 20 & 2.20 & 7.80 & 0.28 & 2.20 & 7.80 & 0.28 & 0.28 \\
\hline 21 & 2.30 & 8.40 & 0.27 & 2.40 & 8.30 & 0.29 & 0.28 \\
\hline 22 & 2.40 & 7.90 & 0.30 & 2.60 & 7.90 & 0.33 & 0.32 \\
\hline 23 & 2.60 & 8.70 & 0.30 & 2.60 & 8.40 & 0.31 & 0.30 \\
\hline 24 & 2.00 & 6.50 & 0.31 & 2.00 & 6.40 & 0.31 & 0.31 \\
\hline 25 & 2.10 & 8.90 & 0.24 & 2.10 & 8.90 & 0.24 & 0.24 \\
\hline 26 & 1.90 & 8.80 & 0.22 & 1.80 & 9.00 & 0.20 & 0.21 \\
\hline 27 & 2.40 & 9.00 & 0.27 & 2.40 & 8.70 & 0.28 & 0.27 \\
\hline 28 & 2.60 & 9.60 & 0.27 & 2.40 & 9.50 & 0.25 & 0.26 \\
\hline 29 & 2.20 & 9.80 & 0.22 & 2.20 & 9.70 & 0.23 & 0.23 \\
\hline 30 & 1.90 & 8.20 & 0.23 & 1.90 & 8.30 & 0.23 & 0.23 \\
\hline 31 & 2.40 & 8.30 & 0.29 & 2.40 & 9.80 & 0.24 & 0.27 \\
\hline 32 & 2.20 & 7.60 & 0.29 & 2.20 & 7.10 & 0.31 & 0.30 \\
\hline 33 & 2.30 & 8.20 & 0.28 & 2.30 & 8.10 & 0.28 & 0.33 \\
\hline 34 & 2.00 & 9.10 & 0.22 & 2.20 & 8.70 & 0.25 & 0.32 \\
\hline Mean \pm SD & $2.24 \pm 0.22$ & $8.02 \pm 0.82$ & $0.283 \pm 0.032$ & $2.24 \pm 0.22$ & $8.06 \pm 0.87$ & $0.282 \pm 0.032$ & $0.27 \pm 0.03$ \\
\hline
\end{tabular}

significant variation between the patients and the right and left control values $(\mathrm{p}=0.31$ and $\mathrm{p}=0.33$, respectively). However, the absolute values for the femoral neck (right and left) were significantly smaller in the controls than in the patients $(p=0.019$ and $p=0.045$ respectively) (Figure 2).

The measurements for the head/neck ratio in the control group, on the right and left sides, did not differ significantly from each other $(0.283 \pm 0.032$ vs. $0.282 \pm 0.032 ; p=0.64)$. Thus, the values from both sides could be compared with the measurements on the patients. The values for group 1 were significantly smaller than the values for group $2(0,255 \pm 0.035$ vs. $0.282 \pm 0.032 ; p=0.004)$ (Figure 3). 


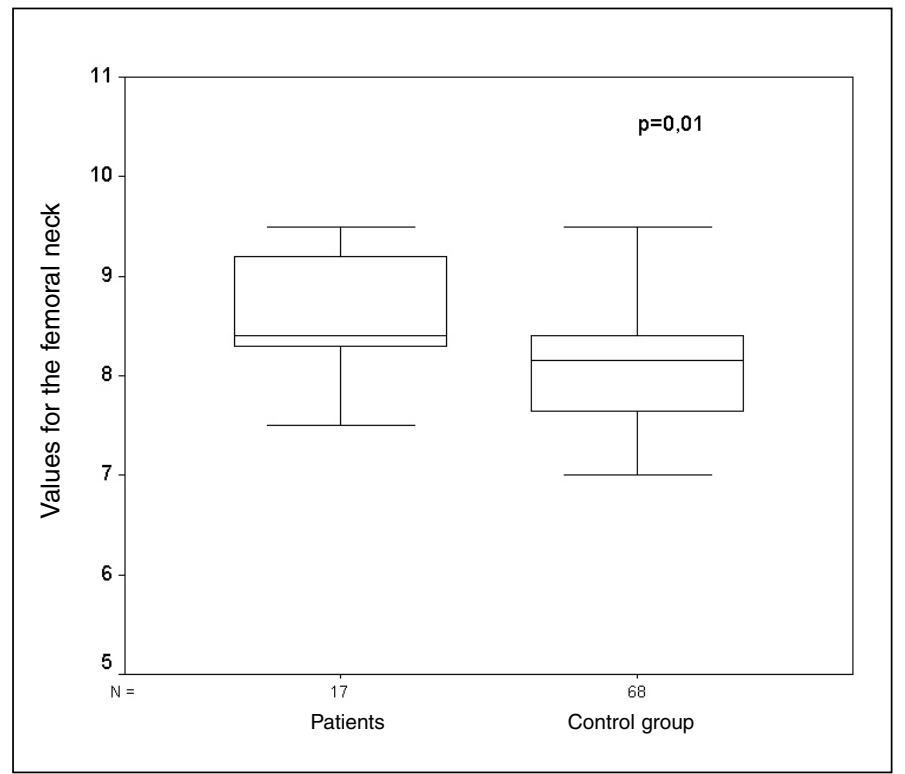

Figure 2 - Box plot presentation of the right and left femoral neck measurement in controls and the femoral neck in patients with epiphysiolysis and in controls.

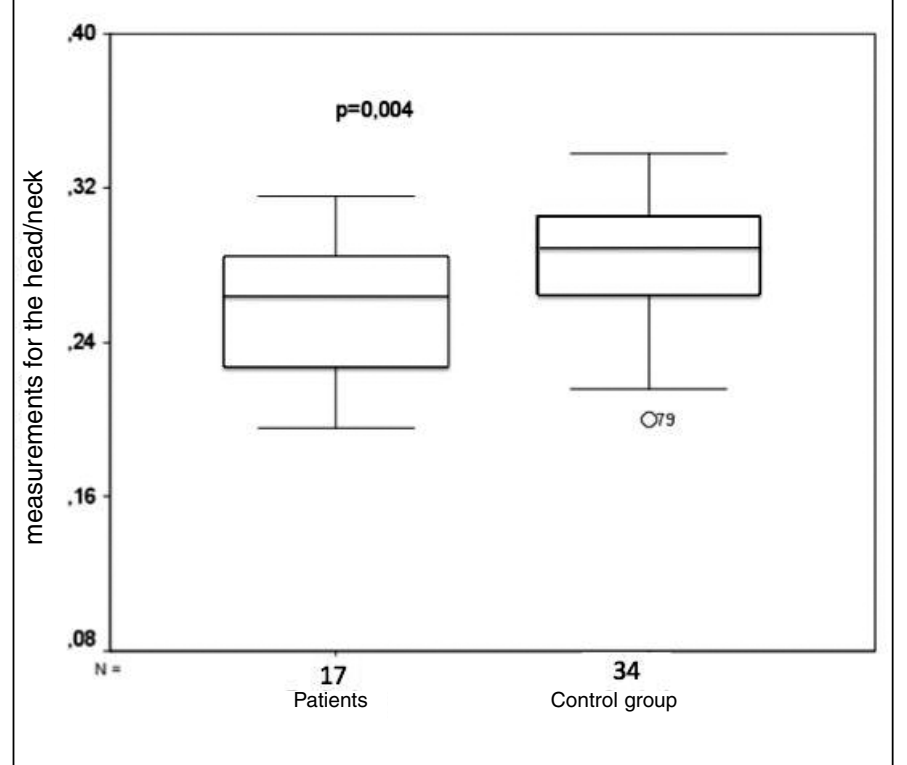

Figure 3 - Box plot presentation of the head height/neck ratio among patients with epiphysiolysis and in controls.

\section{DISCUSSION}

This study assessed whether there was any difference in the head height/neck length ratio of the femur on the contralateral side of patients with unilateral epiphysiolysis, in comparison with a control group. The aim was to determine whether this index might be an indicator for the risk that slippage of the contralateral epiphysis of the femur might occur, given that early diagnosis of contralateral involvement is still a matter of controversy and discussion in the literature $\mathrm{r}^{(1,6-10,16-18)}$. The factors involved in such occurrences are still under investigation, in an attempt to obtain parameters that might, more securely, identify patients who should undergo prophylactic surgical treatment on the contralateral hip, before the disease is manifested with greater morbidity and complications.

The control group seemed to be very adequate, given that it did not differ from the study group. This was not only with regard to age and gender (as inclusion criteria), but also with regard to the profile of the relationship between chronological age and bone age, and in relation to the distribution of BMI, a variable that has recently been included among the risk factors for $\mathrm{PEF}^{(2)}$. In 2005, Manoff et $\mathrm{al}^{(2)}$ reviewed $106 \mathrm{PEF}$ cases and found that $81.6 \%$ were obese, whereas the rate in the control group was $41.38 \%$. Bhatia et $\mathrm{al}^{(19)}$ presented the first study evaluating BMI as a factor associated with PEF with bilateral involvement. From studying 54 patients with PEF, they concluded that the BMI was significantly greater in cases with bilateral involvement. On the other hand, Santili et al ${ }^{(20)}$ demonstrated that obese patients have a greater anteroposterior Southwick angle than seen among non-obese controls. Although the present study found high prevalence of overweight and obesity, both among the patients and among the controls (thus corroborating the vision of an "epidemic of obesity" that has been widely cited in the scientific and lay media), the mean BMI values in the study group were not as high as in other references ${ }^{(2,19)}$. This can perhaps be partly explained by the fact that this sample was selected only from cases with unilateral involvement.

The existence of a discrepancy between the chronological age and the bone age among children with PEF has also been a matter discussed in the literature. In the present study, attention was drawn to the fact that the bone age in both groups (patients and controls) was significantly greater than the chronological age, but without any significant difference when compared between each other. This finding suggests that the study group had skeletal maturation that was similar to that of the control group, and that under this condition, occurrences of new slippage would be practically impossible, considering that according 
to the Oxford scoring, the mean value for the study group was 29.

Considering the adequacy of the control group, the significantly different results regarding the femoral head/neck ratio between the study and control groups are important. The height of the epiphysis and the length of the femoral neck were assessed using radiographs of the proximal contralateral femur, in accordance with the method used by Bleck ${ }^{(12)}$, modified. Separately, it was observed that the head height did not differ significantly between the groups, as might be expected, thus indicating that there was no retroversion or epiphysiolysis of the contralateral hip. On the other hand, the greater neck length may suggest that accentuated growth of the proximal growth plate of the femur had occurred. If this might represent another factor predisposing towards proximal epiphysiolysis of the femur, only complementary prospective studies with imaging examinations of greater sophistication would bring greater elucidation.

\section{CONCLUSION}

It can be stated that there are anatomical radiographic differences in the contralateral head/neck relationship among children with PEF, in comparison with children without this disease.

\section{REFERENCES}

1. Katz DA. Slipped capital femoral epiphysis: the importance of early diagnosis. Pediatr Ann. 2006;35(2):102-11.

2. Manoff EM, Banffy MB, Winell JJ. Relationship between Body Mass Index and slipped capital femoral epiphysis. J Pediatr Orthop. 2005;25(6):744-6.

3. Papavasiliou KA, Kirkos JM, Kapetanos GA, Pournaras J. Potencial influence of hormones in the development of slipped capital femoral epiphysis: a preliminary study. J Pediatr Orthop B. 2007;16(1):1-5.

4. Puylaert D, Dimeglio A, Bentahar T. Staging puberty in slipped capital femoral epiphysis: importance of triradiate cartilage. J Pediatr Orthop. 2004;24(2):144-7.

5. Huberty DP, Szalay EA. Evaluation of bone density in children with slipped capital femoral epiphysis. J Pediatr Orthop. 2006;26(1):13-5

6. Lehmann CL, Arons RR, Loder RT, Vitale MG. The epidemiology of slipped capital femoral epiphysis: an updadte. J Pediatr Orthop. 2006;26(3):286-90.

7. Schultz WR, Weinstein JN, Weinstein SL, Smith BG. Prophylatic pinning of the contralateral hip in slipped capital femoral epiphysis: evaluation of long-term outcome for the contralateral hip with use of decision analysis. J Bone Joint Surg Am. 2002;84(8):1305-14.

8. Bidwell TA, Stott SN. Sequential slipped capital femoral epiphysis: who is at risk for a second slip? ANZ J Surg. 2006;76(11):973-6.

9. MacLean JG, Reddy SK. The contralateral slip. An avoidable complication and indication for prophylactic pinning in slipped upper femoral epiphysis. J Bone Joint Surg Br. 2006;88(11):1497-501.

10. Stasikelis PJ, Sullivan CM, Phillips WA, Polard JA. Slipped capital femoral epiphysis. Prediction of contralateral involvement. J Bone Joint Surg Am. 1996;78(8):1149-55.
11. Loder RT, Starnes T, Dikos G. The narrow window of bone age in children with slipped capital femoral epiphysis: a reassessment one decad later. J Pediatr Orthop. 2006;26(3):300-6.

12. Bleck EE. Idiopathic condrolysis of the hip. J Bone Joint Surg Am. 1983;65(9):126675.

13. Must A, Dallal GE, Dietz WH. Reference data for obesity: 85th a 95th percentiles of body mass index $\left(w t / h^{2}\right)$ and tríceps skinfolds thickness. Am J Clin Nutr. 1991;53(4):839-46.

14. Acheson RM. The Oxford method of assessing skeletal maturity. Clin Orthop Relat Res. 1957;10:19-39.

15. Ishida A, Laredo Filho J, Kuwajima SS, Milani C, Tamanaga F, Fernandes FAS, Yanaguizawa T. Idade esquelética em crianças com doença de Legg-Calvé-Perthes, avaliadas pelo método de Oxford. Rev Bras Ortop. 1999;34(1): 41-6.

16. Aronsson DD, Loder RT, Breur GJ, Weinstein SL. Slipped capital femoral epiphysis: current concepts. J Am Acad Orthop Surg. 2006;14(12):666-79.

17. Barrios C, Blasco MA, Blasco MC, Gascó J. Posterior sloping angle of the capital femoral epiphysis: a predictor of bilaterality in slipped capital femoral epiphysis. J Pediatr Orthop. 2005;25(4):445-9.

18. Loder RT, Mehbod AA, Meyer C, Meisterling M. Acetabular depth and race in young adults: a potential explanation of the prevalence of slipped capital femoral epiphysis between different racial groups. J Pediatr Orthop. 2003;23(6):699702.

19. Bhatia NN, Pirpiris M, Otsuka NY. Body mass index in patients with slipped capital femoral epiphysis. J Pediatr Orthop. 2006;26(2):197-9.

20. Santili C, de Assis MC, Kusabara FI, Romero IL, Sartini CM, Longui CA. Southwick's head-shaft angles: normal standards and abnormal values observed in obesity and in patients with epiphysiolisis. J Pediatr Orthop B. 2004;13(4):244-7. 